\title{
Myoepithelial Carcinoma Arising in a Plasmacytoid Myoepithelioma of the Parotid Gland Synchronized with Melanoma: A Case Report and Review of the Literature
}

\author{
Pamela Denisse Soberanis-Piña ${ }^{a}$ Ricardo Fernández-Ferreira ${ }^{a}$ \\ Héctor Hugo Buerba-Vieregge ${ }^{a} \quad$ Edgar Varela-Santoyo ${ }^{a}$ Jerónimo \\ Rafael Rodriguez-Cid ${ }^{a}$ Andres Macari-Jorge ${ }^{b}$ Rita Dorantes-Heredia ${ }^{b}$ \\ aDepartment of Oncology Medicine, Comprehensive Oncology Center "Diana Laura Riojas \\ de Colosio," Medica Sur Clinic and Foundation, Mexico, Mexico; 'bervice of Anatomical \\ Pathology, Medica Sur Clinic and Foundation, Mexico, Mexico
}

\author{
Keywords \\ Myoepithelial carcinoma - Myoepithelioma - Parotid gland · Plasmacytoid myoepithelioma
}

\begin{abstract}
Myoepithelial carcinoma, also known as malignant myoepithelioma, is considered an extremely rare $(0.45-1 \%)$ malignant salivary gland neoplasm. Approximately 100 cases have been reported in the English-language literature on myoepithelial carcinoma. The majority of the myoepitheliomas described in the literature have been benign, and the malignant counterpart is considered rare $(<1 \%)$. Such a tumor may appear de novo or rarely develop from a preexisting pleomorphic adenoma $(<20 \%)$, and in exceedingly rare cases $(<0.5 \%)$, it has arisen from a benign myoepithelioma (i.e., plasmacytoid myoepithelioma). To our knowledge, no case of myoepithelial carcinoma of the parotid gland arising in a plasmacytoid myoepithelioma synchronized with melanoma has been reported to date. The treatment of myoepithelial carcinoma has been mainly surgical, including wide excision with free margins, with or without nodal dissection. The roles of chemotherapy and radiotherapy have not yet been established. We report a case of myoepithelial carcinoma of the parotid gland arising in a plasmacytoid myoepithelioma synchronized with melanoma in a 40-year-old woman. In our case, a complete response was achieved with surgery followed by adjuvant chemotherapy based on carboplatin and paclitaxel concurrent with radiotherapy.

(C) 2021 The Author(s).




\section{Introduction}

Salivary gland tumors that display myoepithelial differentiation exclusively or predominantly are relatively uncommon, and the assessment of malignancy in a myoepithelial tumor can be difficult. Myoepithelial cell proliferation leads to the formation of rare tumors, both benign myoepitheliomas and malignant myoepithelial carcinomas [1, 2]. Malignant myoepithelioma most often arises de novo, but it occasionally develops in a preexisting pleomorphic adenoma [3-10], and in very rare cases, it has arisen from a benign myoepithelioma (plasmacytoid myoepithelioma). Malignant transformation in myoepithelioma may be a result of genetic mutation [11-15].

Myoepithelial carcinoma, also known as malignant myoepithelioma, is considered an extremely rare (0.45-1\%) malignant salivary gland neoplasm. Myoepitheliomas are lesions characterized by presentation of exclusively myoepithelial differentiation with three main cell patterns: epithelioid (60\%), plasmacytoid $(12 \%)$ or spindle $(8 \%)$, or a mixture of these $(20 \%)[1,2,16]$. Most of these tumors are located in the parotid gland (50\%), while others occur in the sublingual gland (33\%), in the submandibular gland (13\%), or in other parts (soft tissue, skin, retroperitoneum, lung, larynx, nasopharynx, palate, and breast) [17-19].

Myoepitheliomas are most common in young adults between the ages of 30 and 50 years, with the average age of patients at 36.3 years, with no gender predominance [20,21]. Their biological behavior is variable, with a high tendency for local recurrence and less frequently distant metastases. Less than $20 \%$ of lesions derive from a benign lesion, especially recurrent pleomorphic adenoma, and in exceedingly rare cases $(<0.5 \%)$, they have arisen from a benign myoepithelioma (plasmacytoid myoepithelioma) [1-10, 17-21].

We report a case of myoepithelial carcinoma of the parotid gland arising in a plasmacytoid myoepithelioma synchronized with melanoma in a 40-year-old woman, which has not been reported in the literature.

\section{Case Report}

A 36-year-old woman presented with a 4-month history of a progressive and painful increase in volume of the parotid. In March 2018, a superficial parotidectomy with preservation of the facial nerve was performed, with histopathological findings of plasmacytoid myoepithelioma (shown in Fig. 1).

In October 2018, she presented with a de novo macular lesion in the right frontal region, asymmetric and hyperpigmented, with spontaneous bleeding. Excision was performed, with a report of cutaneous nodular melanoma, not ulcerated, with a Breslow thickness of $2.1 \mathrm{~mm}$, and without lymphovascular or perineural invasion. Subsequently, a combined $2-\left[{ }^{18} \mathrm{~F}\right]$-fluoro2-deoxy-D-glucose positron emission tomography/computed tomography ( ${ }^{18} \mathrm{FDG}$-PET/CT) was performed as an extension study, which demonstrated the presence of right cervical lymphadenopathy at levels IIA and IIB, the largest being $25 \times 15 \mathrm{~mm}$ in size. The patient was assessed for oncological surgery, and total parotidectomy with modified radical cervical dissection was planned for what was thought to be a recurrent plasmacytoid myoepithelioma. The histopathological examination revealed the frontal region without evidence of melanoma and the cervical region with evidence of metastatic myoepithelial carcinoma of the parotid gland, with 18 of 55 nodes positive at a Ki-67 proliferation index of $10 \%$ (Fig. $2 \mathrm{~A}, \mathrm{~B}, 3)$.

It was staged IVA, so that adjuvant treatment with radiotherapy at 66 Gy to the right cervical region (total: 33 sessions) and concomitant chemotherapy (carboplatin AUC $2+$ paclitaxel $80 \mathrm{mg} / \mathrm{m}^{2}$ ) was performed. A complete response was reported (Fig. 2C, D).

\section{Karger'}




\section{Case Reports in Oncology}

\begin{tabular}{l|l}
\hline Case Rep Oncol 2021;14:173-183 \\
\hline DOI: 10.1159/000510937 & $\begin{array}{l}\text { ○ 2021 The Author(s). Published by S. Karger AG, Basel } \\
\text { www.karger.com/cro }\end{array}$ \\
\hline
\end{tabular}

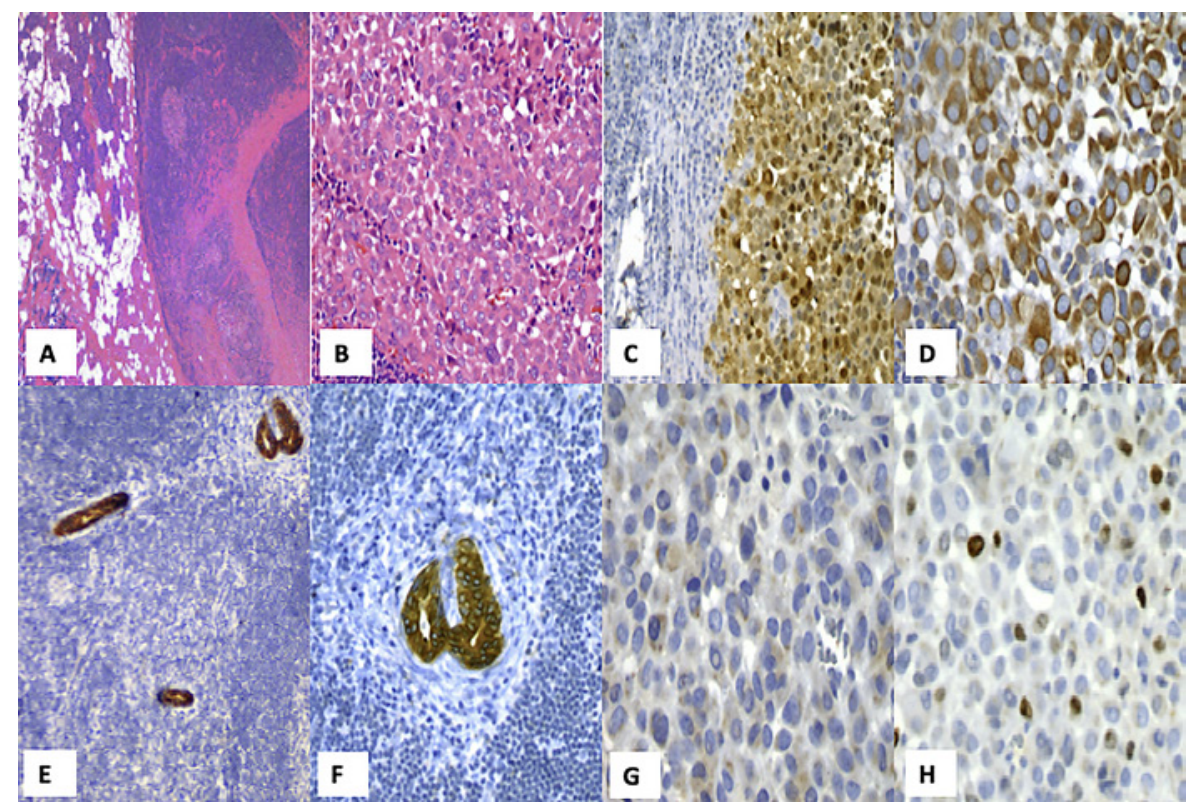

Fig. 1. Plasmacytoid myoepithelioma of the parotid gland. A Panoramic view ( $\times 4$ ). On the left side, it presents normal parotid gland tissue, and on the right side, there is a well-defined solid neoplastic lesion. B Medium magnification $(\times 10)$. Neoplasm of myoepithelial cells with epithelioid and plasmacytoid appearance and nonspecific inflammatory infiltrate. C S100 protein-positive nucleus and cytoplasm. D Cytoplasm positive for vimentin. E, F Negative for broad-spectrum cytokeratin (positive internal control in trapped ducts). G Cytoplasm weakly positive for calponin. $\mathbf{H}$ Nuclei positive for Ki-67 in 10-15\% of the neoplastic cells.

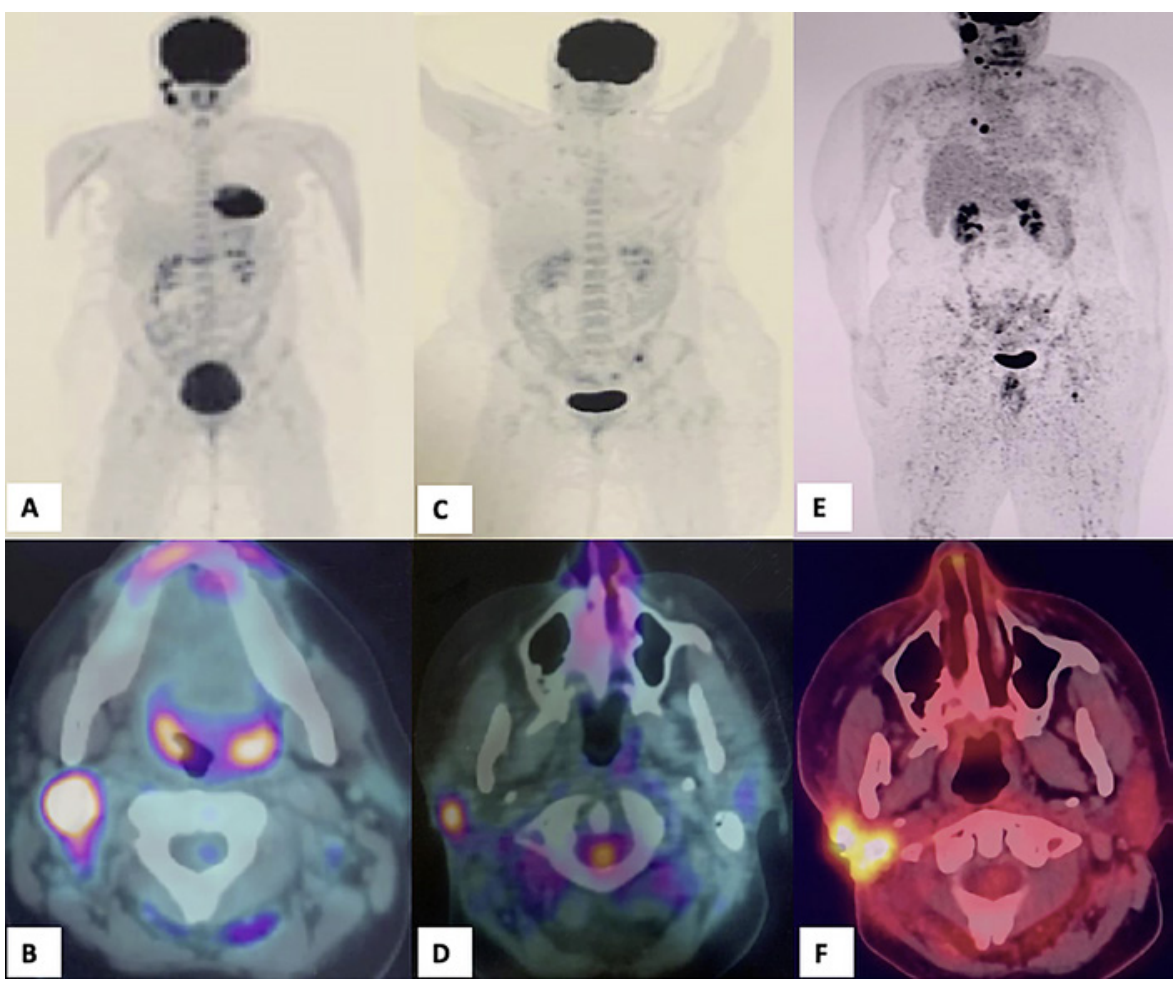

Fig. 2 A, B ${ }^{18}$ FDG-PET/CT showed the presence of right cervical lymphadenopathy at levels IIA and IIB. C, D A complete response to radiotherapy and chemotherapy was shown. E, $\mathbf{F}$ Ten months later, local recurrence and metastasis to the lung were demonstrated. 


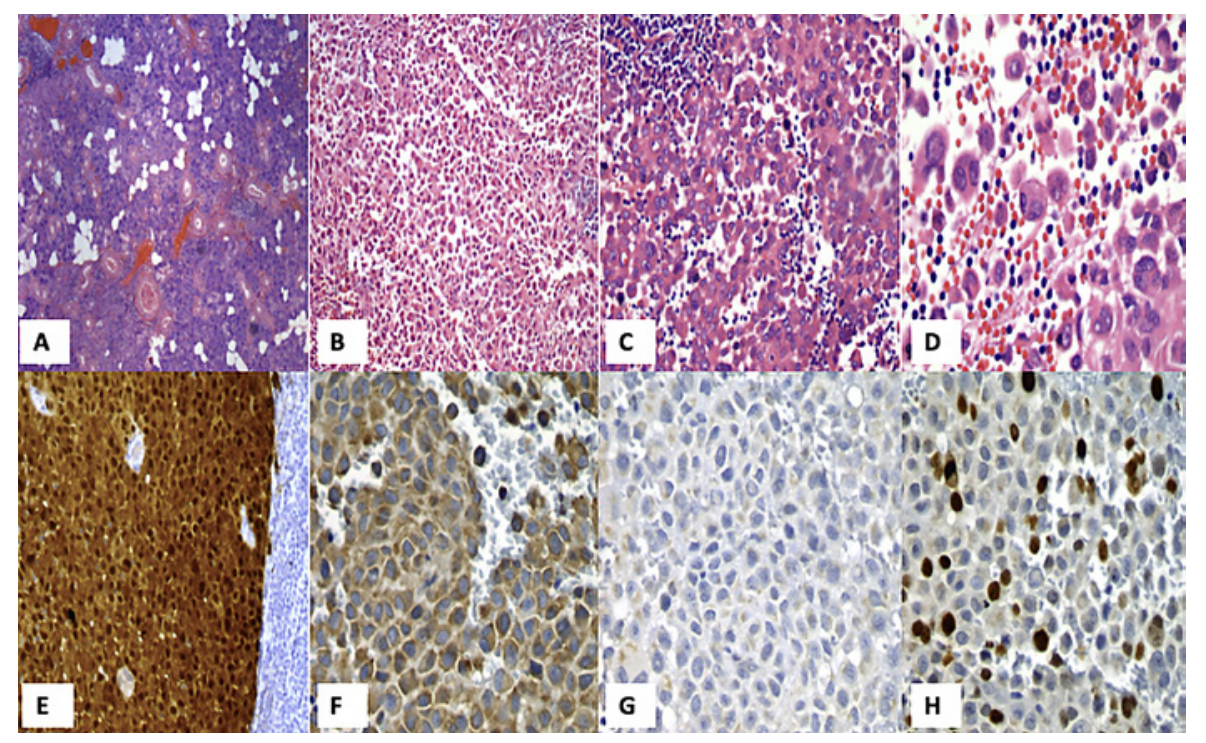

Fig. 3. A Parotid gland without histological alterations. B Medium magnification $(\times 20)$. Trabecular-pattern myoepithelial carcinoma with lymph node infiltration (upper right corner and middle right side of the image). C Neoplastic cells with epithelioid and plasmacytoid appearance infiltrating the lymph node. D High magnification $(\times 40)$. Nuclear atypia, binucleation, and cells with nuclei rejected to the periphery. E Cytoplasm and nuclei positive for S100 protein. F Diffuse weak cytoplasmic positivity for calponin. G Negativity for p63. H Positivity for Ki-67 in 5-10\% of the nuclei of the neoplastic cells.

Ten months after the operation, control ${ }^{18} \mathrm{FDG}$-PET/CT was performed, in which local recurrence and metastasis to the lung were shown. The lesion was examined by biopsy, and diagnosed as metastatic melanoma of the lung, parotid gland, and preauricular region (Fig. 2E, $F, 4)$.

\section{Discussion}

Malignant myoepithelioma is one of the rarest salivary gland neoplasms. Sheldon et al. first used the term "myoepithelioma" in 1943 to describe 3 cases; however, the first description of a clearly malignant myoepithelioma is attributed to Stromeyer et al. in 1975 [3, 22-24]. The majority of the myoepitheliomas described in the literature have been benign, and the malignant counterpart is considered rare $(<1 \%)$. Such a tumor may appear de novo or rarely develop from a preexisting pleomorphic adenoma $(<20 \%)$, and in exceedingly rare cases $(<0.5 \%)$, it has arisen from a benign myoepithelioma (i.e., plasmacytoid myoepithelioma) [3-15].

In cases of carcinoma ex plasmacytoid myoepithelioma, both carcinoma and plasmocytoid components are supposed to exist in the primary lesion. However, it is often difficult to demonstrate a preexisting plasmacytoid myoepithelioma because the malignant component may overgrow the other component [11-16, 20-23]. In the present case, there was no evidence of the existence of plasmacytoid myoepithelioma in the recurrent tumor, despite examination of multiple sections. Nonetheless, the present neoplasm was supposed to be a "myoepithelial carcinoma ex plasmacytoid myoepithelioma."

Malignant myoepithelioma was included in the updated histological classification of salivary gland tumors by the World Health Organization in 1991, and its definition was 


\section{Case Reports in Oncology}

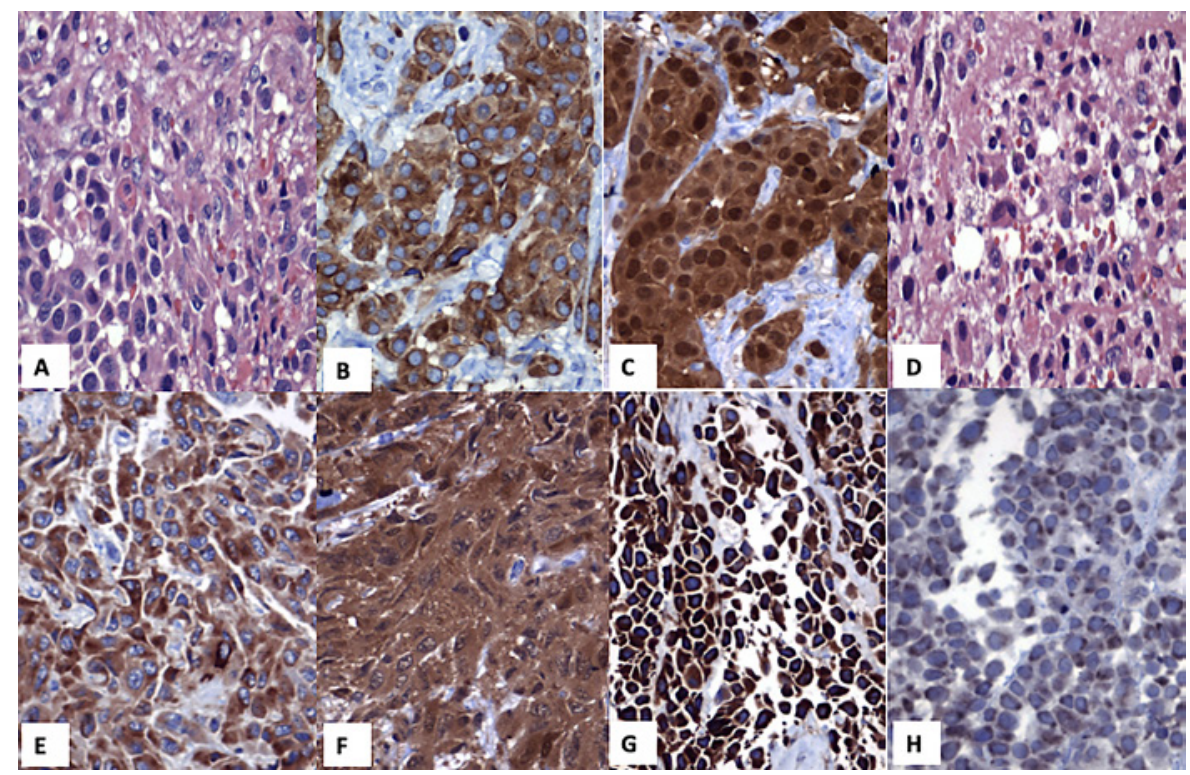

Fig. 4. A Lung nodule. High magnification $(\times 40)$. Neoplastic cells forming nests or islands. Up to 3 mitosis figures per field. B, C Immunohistochemistry of the lung: positive for HMB-45 (B) and S100 protein (C). D Parotid. High magnification $(\times 40)$. Round-core neoplastic cells with vesicular chromatin and an evident nucleolus with eosinophilic cytoplasm. E, F Parotid immunohistochemistry: positive for HMB-45 (E) and S100 protein (F) and negative for calponin. G, H Immunohistochemistry of the preauricular region: positive for HBM-45 (G) and melan-A (H).

updated in 2005 [1,25,26]. Approximately 100 cases have subsequently been reported in the English-language literature. However, a myoepithelial carcinoma arising in a plasmacytoid myoepithelioma of the parotid gland synchronized with melanoma has not yet been reported in the literature. It remains controversial whether this neoplasm was classified as a myoepithelial carcinoma or a carcinoma ex pleomorphic adenoma or plasmacytoid myoepithelioma in the classification by the WHO in 2005. Most of these tumors are located in the parotid gland, while others occur in the submandibular gland or in the accessory glands of the oral cavity and other sites (hard and soft palate, lip, cheek, tongue, floor of the mouth, gingiva, retromolar area, larynx, nasopharynx, skin, retroperitoneum, lung, and breast) $[1,3-7,9,10,15,17,18$, 21-25, 27-42].

In general, myoepitheliomas are most common in young adults between the ages of 30 and 50 years, with the average age at 36.3 years, with no gender predominance [20-24], but in carcinoma ex pleomorphic adenoma or plasmacytoid myoepithelioma, most cases occur in the age range of 14-77 years, at an average age of 57 years. There is a female predominance, with a male-to-female ratio of $0.87: 1[1,16,24,27,30,41]$.

The clinical presentation is usually the development of a painless mass in the head and neck, with an average evolution time of 5 months. These lesions are considered to have two stages of growth: a slow onset, followed by a phase of rapid and aggressive growth [41].

The diagnosis is made through biopsy of the lesion with histological confirmation. Histologically, they are heterogeneous, in most cases with a mixed component. The currently accepted diagnostic criteria for myoepithelial carcinoma are exclusive myoepithelial differentiation (morphologic and immunohistochemical) and clear-cut tumor infiltration into the adjacent salivary gland or other tissues. Only a few fulfill the criteria for being classified as malignant. These criteria are invasion and destructive growth, cellular pleomorphism, and 
presence of mitosis. Recently, Nagao et al. [7] suggested that a high cell proliferative activity (i.e., 7 mitosis instances per $10 \mathrm{HPF}$ or a Ki-67 labeling index $>10 \%$ ) may indicate malignancy $[7,43]$.

Cytogenetic analyses performed on myoepitheliomas have demonstrated the presence of a 12q12 translocation. This alteration usually also occurs in pleomorphic adenoma, which supports the hypothesis of a common precursor to both myoepithelial and ductal epithelial cells [44].

They can express vimentin and S100, being very sensitive but not very specific. Other useful markers are cytokeratin, alpha-smooth muscle actin, and myoepithelial markers such as calponin, p27, p53 and CAM $5.2[41,45]$. In an immunohistochemical analysis of 51 patients, positivity was reported for vimentin (100\%), calponin (98\%), S100 (82\%), smooth muscle actin (35\%), and cytokeratin (74\%), as well as negativity for carcinoembryonic antigen in $100 \%$ of cases [43]. The malignant component is usually characterized by the presence of infiltration, necrotic areas, cellular atypia, a high rate of mitosis, and cellular pleomorphism. It usually lacks epithelial ductal differentiation and is less composed of stromal elements. The cellular composition may include spindle cells (45\%), plasmacytoids (7.5\%), and epithelial $(32.5 \%)$ or clear cells $(2.5 \%)$, the presence of more than two types of cell population being the most frequent $[41,45]$. The absence of expression of carcinoembryonic antigen is what can differentiate it from epithelial-myoepithelial carcinoma.

The differential diagnosis of myoepithelial carcinoma includes a wide range of neoplasms, depending on the predominant cell type. It is sometimes difficult to differentiate myoepithelial carcinoma showing epithelioid morphologic characteristics from other salivary gland neoplasms showing myoepithelial differentiation, especially adenoid cystic carcinoma, polymorphous low-grade carcinoma, and others. Demonstration of luminal differentiation by carcinoembryonic antigen and epithelial membrane antigen immunostaining favors the diagnosis of adenoid cystic carcinoma [1,43]. In tumors with clear-cell morphologic characteristics, the differential diagnosis includes hyalinizing clear-cell carcinoma, epithelial-myoepithelial carcinoma, and metastatic renal cell carcinoma [46]. Melanoma, high-grade lymphoma, or plasmacytoma must be ruled out when the tumor shows plasmacytoid differentiation. With spindle cell morphologic characteristics, the most common differentials are sarcomatoid squamous carcinoma, spindle cell melanoma, and schwannoma. To help distinguish between them, the diagnostician should use specific morphologic criteria like melanin pigment, prominent eosinophilic nucleoli (melanoma), a biphasic pattern with luminal differentiation (adenoid cystic carcinoma and epithelial-myoepithelial carcinoma), Antoni A and Antoni B areas (schwannoma), and an in situ squamous component (sarcomatoid squamous carcinoma) in combination with appropriate immunohistochemical analyses $[43,47,48]$.

The biological behavior of myoepithelial carcinoma is usually variable, with high recurrence rates (35\%) and less frequently distant metastases (13\%) [43, 45]. Up to $40 \%$ of patients have been reported to have local recurrence, and 30\% have distant metastases with myoepithelial soft tissue carcinoma [49]. It has been reported that it should even be classified as a high-grade neoplasm with a poor prognosis. In a study of 27 patients, $59 \%$ presented local recurrence and $22 \%$ distant metastases. The presence of metastases is usually from months to several years after resection [50]. Rarely do they present distant metastases; however, metastatic sites mentioned in case reports include the lungs, kidneys, brain, liver, pleura, peritoneum, and skin. Factors that may be associated with greater recurrence are cell type (greater in clear cells), tumor length, and perineural invasion, and those associated with a higher risk of metastasis have been described as positive margins, areas of extensive necrosis, nuclear atypia, and a high mitotic index $[9,43,51-54]$. The evidence is based on retrospective studies with small numbers of patients, but it seems that local recurrence rates are high and with a high metastatic potential.

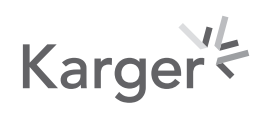


Currently, there is no consensus with regard to the treatment of head and neck myoepithelial carcinoma, due to its rarity. Wide surgical excision is always the first choice for localized tumors. With a high local recurrence rate, initial surgery should be radical with sufficient disease-free margins. As the most common site is the parotid gland, tumor invasion of the facial nerve may occur. Attempts should be made to preserve the facial nerve if the primary tumor is small and/or is far away from the facial nerve [41, 55]. Therefore, elective neck dissection is not recommended routinely, and it is only applied when large cervical nodes are present due to a low degree of involvement $(<10 \%)[41,50]$. In patients with a clinically negative neck, it was reported that performing lymph node sampling or dissection does not impact overall survival and the possibility of presenting hidden metastases is less than 5\%. Among the possible factors that help predict lymph node involvement, the histological grade has been mainly described [56].

The efficacy of adjuvant therapy has been assessed in case reports and small retrospective studies [41,57]. Radiotherapy is used as an initial therapy if surgery is contraindicated, or as adjuvant therapy if a high risk of recurrence or metastasis is perceived, such as perineural invasion or vascular embolism. An analysis of the National Cancer Database (2004-2013) was performed, identifying 8,243 patients with tumors of the major salivary glands, mainly the parotid in $90 \%$ of cases, and including patients with carcinoma ex pleomorphic adenoma, who underwent surgery. Later they were stratified according to risk. Those at high risk had extracapsular extension or positive margins. Those in the intermediate group were those with any of the following characteristics: pT3 or $\mathrm{T} 4, \mathrm{~N}+, 2$ or 3 histological grade, lymphovascular invasion, or adenoid cystic carcinoma. Only those at high risk were reported to have experienced an impact on overall survival when adding radiotherapy to treatment [58].

In a retrospective analysis that included 92 postoperative patients with myoepithelial carcinoma, adjuvant radiotherapy demonstrated an impact on overall survival in high-grade (III or IV) patients, with statistical significance [57]. Likewise, in another retrospective study conducted in China, 23 patients were assessed, of whom 18 underwent surgery and 9 received adjuvant radiotherapy (50-60 Gy). The survival rates at 3 and 5 years were 59\% and 31.8\%, respectively. The local failure rate was $30.4 \%$, and 8 patients presented distant metastases, with the lung being the most affected site. There was no difference in survival or local control rates between those who received surgery and those who received surgery and radiation therapy ( $p=0.059)$ [41]. The disease-free survival reported in an analysis of 51 cases was 31.9 months [43]. In a separate case report of myoepithelial carcinoma of the head and neck by Nieder et al. [59], postoperative radiotherapy after incomplete surgical resection also did not benefit local control and survival. A clinical study from the Peking University of China [49] gave similar results, with 8 out of 12 patients developing a recurrence after postoperative radiotherapy.

With regard to chemotherapy, the literature is more sparse. Xu et al. [41] reported 5 patients who received chemotherapy; 3 received the MAID regimen for sarcoma, as follows: ifosfamide $\left(2,500 \mathrm{mg} / \mathrm{m}^{2} /\right.$ day, continuous intravenous [CIV], days 1-3), doxorubicin (15 mg/ $\mathrm{m}^{2} /$ day, CIV, days $\left.1-4\right)$, and dacarbazine $\left(250 \mathrm{mg} / \mathrm{m}^{2}\right.$, CIV, days $\left.1-4\right)$, and 2 received paclitaxel $\left(175 \mathrm{mg} / \mathrm{m}^{2}, \mathrm{CIV}\right.$, day 1$)$ and carboplatin (AUC $=5$ or 6$)$ with dacarbazine $\left(125 \mathrm{mg} / \mathrm{m}^{2}\right.$, CIV, days 1-5), which usually entailed between 2 and 4 cycles of chemotherapy. Two patients achieved a partial response with the MAID regimen. Although myoepithelial carcinoma can recur and distal metastases may occur, it might be chemosensitive to the sarcoma chemotherapy regimen. Takayama et al. [60] and Noronha et al. [61] reported useful and sustained responses to intra-arterial cisplatin with irradiation, or intravenous cisplatin/carboplatin in combination with paclitaxel in separate case reports for malignant myoepitheliomas arising in the head and neck or vulva. However, Nieder et al. [59] found no response to ifosfamide or BCNU. The choice of drugs was dictated by the epithelial nature of the tumor. However, whether survival was improved by this treatment is speculative and impossible to assess. In

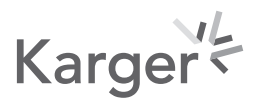


our case, a complete response was achieved with surgery followed by adjuvant chemotherapy based on carboplatin and paclitaxel concurrent with radiotherapy; however, the patient presented metastatic recurrence due to synchronous melanoma.

In 2006, the National Cancer Institute published the Surveillance, Epidemiology, and End Results (SEER) monograph New Malignancies among Cancer Survivors: SEER Cancer Registries, 1973-2000 [62], which evaluated the risk of new malignant tumors after cutaneous malignant melanoma and other first primary cancers. The monograph found that the overall risk of subsequent primary cancers, excluding nonmelanoma skin cancers, increased by $24 \%$ among melanoma survivors and that more than $20 \%$ of the new malignant tumors were also melanomas. Bradford et al. [63] reported that the most common cancers with elevated risks after an initial melanoma were prostate cancer (O:E, 1.15; EAR, 3.49), female breast cancer $(1.10 ; 1.34)$, and non-Hodgkin lymphoma (NHL) $(1.25 ; 1.18)$. Risks were also significantly increased for cancers of the salivary gland, small intestine and kidney, ocular melanoma, and thyroid cancer, as well as for soft tissue sarcomas and chronic lymphocytic leukemia.

\section{Conclusions}

We reported a case of myoepithelial carcinoma of the parotid gland arising in a plasmacytoid myoepithelioma synchronized with melanoma in a 40-year-old woman, which has not been reported yet in the literature. A complete response was achieved with surgery followed by adjuvant chemotherapy based on carboplatin and paclitaxel concurrent with radiotherapy.

\section{Acknowledgments}

Thanks are due to the Southern Medical Hospital for their support in data collection.

\section{Statement of Ethics}

The patient gave his informed written consent to publish his case (including the publication of images).

\section{Conflict of Interest Statement}

The authors have no conflicts of interest to declare.

\section{Funding Sources}

No funding was received.

\section{Author Contributions}

P.D. Soberanis-Piña and R. Fernández-Ferreira contributed to the conception of the case, analysis and critical revision of the content, and the final approval of the version to be published. H.H. Buerba-Vieregge, E. Varela-Santoyo, and J.R. Rodriguez-Cid contributed to 
critical revision of the content, as well as the final approval of the version to be published. $\mathrm{R}$. Dorantes-Heredia and A. Macari-Jorge carried out the exhaustive review of the histopathological characteristics of cancer and analysis of the article. All authors agree to be responsible for all aspects of the work to ensure that questions related to the accuracy or completeness of any part of the paper are properly investigated and resolved.

\section{References}

1 Savera AT, Sloman A, Huvos AG, Klimstra DS. Myoepithelial carcinoma of the salivary glands: a clinicopathologic study of 25 patients. Am J Surg Pathol. 2000;24(6):761-74.

2 Ellis G, Auclair P. Benign epithelial neoplasms. In: Ellis GL, Auclair PL. Tumors of the salivary glands. Washington, DC: Armed Force Institute of Pathology; 2002. vol. 57; p. 57-68.

3 Di Palma S, Guzzo M. Malignant myoepithelioma of salivary glands: clinicopathological features of ten cases. Virchows Arch A Pathol Anat Histopathol. 1993;423(5):389-96.

4 Suba Z, Németh Z, Gyulai-Gaál S, Ujpál M, Szende B, Szabó G. Malignant myoepithelioma. Clinicopathological and immunohistochemical characteristics. Int J Oral Maxillofac Surg. 2003;32(3):339-41.

5 Ibrahim R, Bird DJ, Sieler MW. Malignant myoepithelioma of the larynx with massive metastatic spread to the liver: an ultrastructural and immunocytochemical study. Ultrastruct Pathol. 1991;15(1):69-76.

6 Kim HS, Lee WM, Choi SM. Myoepitheliomas of the soft palate: helical CT findings in two patients. Korean J Radiol. 2007;8(6):552-5.

7 Nagao T, Sugano I, Ishida Y, Tajima Y, Matsuzaki O, Konno A, et al. Salivary gland malignant myoepithelioma: a clinicopathologic and immunohistochemical study of ten cases. Cancer. 1998;83(7):1292-9.

8 McCluggage WG, Primrose WJ, Toner PG. Myoepithelial carcinoma (malignant myoepithelioma) of the parotid gland arising in a pleomorphic adenoma. J Clin Pathol. 1998;51(7):552-6.

9 Parwani AV, Lujan G, Ali SZ. Myoepithelial carcinoma arising in a pleomorphic adenoma of the parotid gland: report of a case with cytopathologic findings. Acta Cytol. 2006;50(1):93-6.

10 AIós L, Cardesa A, Bombí JA, Mallofré C, Cuchi A, Traserra J. Myoepithelial tumors of salivary glands: a clinicopathologic, immunohistochemical, ultrastructural, and flow-cytometric study. Semin Diagn PathoI. 1996; 13(2):138-47.

11 Bakshi J, Parida PK, Mahesha V, Radotra BD. Plasmacytoid myoepithelioma of palate: three rare cases and literature review. J Laryngol Otol. 2007;121(9):e13.

12 Santos EP, Cavalcante DR, Melo AU, Pereira JC, Gomes MZ, Albuquerque RL Jr. Plasmacytoid myoepithelioma of minor salivary glands: report of case with emphasis in the immunohistochemical findings. Head Face Med. 2011;7:24.

13 Perez DE, Lopes MA, de Almeida OP, Jorge J, Kowalski LP. Plasmacytoid myoepithelioma of the palate in a child. Int J Paediatr Dent. 2007;17(3):223-7.

14 Talebi A, Pooralborzi F, Basir HR, Okhovvat AR, Moghaddas D. Plasmacytoid myoepithelioma of the palate with rapid growth: a case report. Iranian J Pathol. 2007;2:115-7.

15 Politi M, Toro C, Zerman N, Mariuzzi L, Robiony M. Myoepithelioma of the parotid gland: case report and review of literature. Oral Oncol Extra. 2005;41:104-8.

16 Dardick I, Cavell S, Boivin M, Hoppe D, Parks WR, Stinson J, et al. Salivary gland myoepithelioma variants. Histological, ultrastructural and immunocytological features. Virchows Arch A Pathol Anat Histopathol. 1989(416):25-42.

17 Acikalin MF, Pasaoglu O, Cakli H, Gürbüz K, Canaz F. Malignant myoepithelioma of the palate: a case report with review of the clinicopathological characteristics. Yonsei Med J. 2009;50(6):848-51.

18 Sciubba JJ, Brannon RB. Myoepithelioma of salivary glands: report of 23 cases. Cancer. 1982;49(3):562-72.

19 Ellis GL, Auclair PL. Tumors of the salivary glands. Washington, DC: Armed Force Institute of Pathology; 1995. vol. 57; p. 65.

20 Cuadra Zelaya F, Quezada Rivera D, Tapia Vazquez JL, Paez Valencia C, Gaitán Cepeda LA. Plasmacytoid myoepithelioma of the palate. Report of one case and review of the literature. Med Oral Patol Oral Cir Bucal. 2007; 12(8):E552-5.

21 Tralongo V, Rodolico V, Burruano F, Tortorici S, Mancuso A, Daniele E. Malignant myoepithelioma of the minor salivary glands arising in a pleomorphic adenoma. Anticancer Res. 1997;17(4A):2671-5.

22 Bombí JA, Alós L, Rey MJ, Mallofré C, Cuchi A, Trasserra J, et al. Myoepithelial carcinoma arising in a benign myoepithelioma: immunohistochemical, ultrastructural, and flow-cytometrical study. Ultrastruct Pathol. 1996;20(2):145-54.

23 Kuwabara H, Uda H, Miyabe K, Saito K, Shibanushi T. Malignant plasmacytoid myoepithelioma of the palate: Histological observations compared to benign predominant plasmacytoid myoepithelial cells in pleomorphic adenoma of the palate. Ultrastruct Pathol. 1998;22(2):153-60.

24 Dean A, Sierra R, Alamillos FJ, Lopez-Beltran A, Morillo A, Arévalo R, et al. Malignant myoepithelioma of the salivary glands: clinicopathological and immunohistochemical features. Br J Oral Maxillofac Surg. 1999;37(1): 64-6. 
25 Seifert G, Sobin LH. Histological typing of salivary gland tumours. (WHO. World Health Organization. International Histological Classification of Tumours). 2nd ed. New York: Springer-Verlag; 1991.

26 Skálová A, Jäkel KT, Barnes L, Eveson JW, Reichart PA, editors. Pathology and genetics of head and neck tumours. World Health Organization Classification of Tumours. Lyon: IARC Press; 2005. p. 240-1.

27 Singh R, Cawson RA. Malignant myoepithelial carcinoma (myoepithelioma) arising in a pleomorphic adenoma of the parotid gland. An immunohistochemical study and review of the literature. Oral Surg Oral Med Oral Pathol. 1988;66(1):65-70.

28 Sheldon WH. So-called mixed tumours of the salivary glands. Arch Pathol. 1943;35:1-20.

29 Stromeyer FW, Haggitt RC, Nelson JF, Hardman JM. Myoepithelioma of minor salivary gland origin. Light and electron microscopical study. Arch Pathol. 1975;99(5):242-5.

30 Yang S, Li L, Zeng M, Zhu X, Zhang J, Chen X. Myoepithelial carcinoma of intraoral minor salivary glands: a clinicopathological study of 7 cases and review of the literature. Oral Surg Oral Med Oral Pathol Oral Radiol Endod. 2010;110(1):85-93.

31 Takeda Y. Malignant myoepithelioma of minor salivary gland origin. Acta Pathol Jpn. 1992;42(7):518-22.

32 Toto PD, Hsu DJ. Product definition in a case of myoepithelioma. Oral Surg Oral Med Oral Pathol. 1986;62(2): 169-74.

33 Guzzo M, Cantù G, Di Palma S. Malignant myoepithelioma of the palate: report of case. J Oral Maxillofac Surg. 1994;52(10):1080-2.

34 Carinci F, Grasso DL, Grandi E, Pelucchi S, Pastore A. Malignant myoepithelioma of the tongue base: case report and literature review. J Craniofac Surg. 2001;12(6):544-6.

35 Chhieng DC, Paulino AF. Cytology of myoepithelial carcinoma of the salivary gland. Cancer. 2002;96(1):32-6.

36 Yoshizaki T, Himi Y, Minato H, Ogawa I, Nikai H, Furukawa M. Malignant myoepithelioma arising from recurrent pleomorphic adenoma of minor salivary gland. Auris Nasus Larynx. 2002;29(1):91-4.

37 Magrini E, Pragliola A, Farnedi A, Betts CM, Cocchi R, Foschini MP. Cytogenetic analysis of myoepithelial cell carcinoma of salivary gland. Virchows Arch. 2004;444(1):82-6.

38 Karatzanis AD, Drivas EI, Giannikaki ES, Lachanas VA, Hatziioannou JK, Velegrakis GA. Malignant myoepithelioma arising from recurrent pleomorphic adenoma of the soft palate. Auris Nasus Larynx. 2005;32(4):435-7.

39 Gupta K, Dey P, Das A. Cytomorphological features of a metastatic myoepithelial carcinoma arising in a minor salivary gland. Diagn Cytopathol. 2005;33(1):56-7.

40 Bellizzi AM, Mills SE. Collagenous crystalloids in myoepithelial carcinoma: report of a case and review of the literature. Am J Clin Pathol. 2008;130(3):355-62.

41 Xu T, Liao Z, Tang J, Guo L, Qiu H, Gao Y, et al. Myoepithelial carcinoma of the head and neck: a report of 23 cases and literature review. Cancer Treat Commun. 2014;2(2-3):24-9.

42 Guo C, Asai J, Kan S, Nomiyama T, Takenaka H, Konishi E, et al. Myoepithelial carcinoma on the right shoulder: case report with published work review. J Dermatol. 2016;43(9):1083-7.

43 Kane SV, Bagwan IN. Myoepithelial carcinoma of the salivary glands: a clinicopathologic study of 51 cases in a tertiary cancer center. Arch Otolaryngol Head Neck Surg. 2010;136(7):702-12.

44 Nayak JV, Molina JT, Smith JC, Branstetter BF 4th, Hunt JL, Snyderman CH. Myoepithelial neoplasia of the submandibular gland: case report and therapeutic considerations. Arch Otolaryngol Head Neck Surg. 2003; 129(3):359-62.

45 Branstetter E, Pavon I, Armato E, Cavaleri S, Capuzzo P, Ianniello F. Myoepithelioma of a minor salivary gland of the cheek: case report. Acta Otorhinolaryngol Ital. 2006;26(1):43-6.

46 Cavaleri NS, Botti G, Ionna F, Pasquinelli G, Minenna P, Bisceglia M. Clear-cell myoepithelial carcinoma of the salivary glands: a clinicopathologic, immunohistochemical, and ultrastructural study of two cases involving the submandibular gland with review of the literature. Pathol Res Pract. 2008;204(5):335-44.

47 Said S, Campana J. Myoepithelial carcinoma ex pleomorphic adenoma of salivary glands: a problematic diagnosis. Oral Surg Oral Med Oral Pathol Oral Radiol Endod. 2005;99(2):196-201.

48 Simpson RH. Myoepithelial tumors of the salivary glands. Curr Diagn Pathol. 2002;8(5):328-37.

49 Hornick JL, Fletcher CD. Myoepithelial tumors of soft tissue: a clinicopathologic and immunohistochemical study of 101 cases with evaluation of prognostic parameters. Am J Surg Pathol. 2003;27(9):1183-96.

50 Yu G, Ma D, Sun K, Li T, Zhang Y. Myoepithelial carcinoma of the salivary glands: behavior and management. Chin Med J (Engl). 2003;116(2):163-5.

51 Lauro S, Trasatti L, Larosa G, Calabretta F, Di Gioia CR, Vecchione A. Myoepithelial carcinoma of parotid gland: a case report. Anticancer Res. 2003;23(3C):3041-4.

52 Ohba S, Fujimori M, Ito S, Matsumoto F, Hata M, Takayanagi H, et al. A case report of metastasizing myoepithelial carcinoma of the parotid gland arising in a recurrent pleomorphic adenoma. Auris Nasus Larynx. 2009; 36(1):123-6.

53 Gleason BC, Fletcher CD. Myoepithelial carcinoma of soft tissue in children: an aggressive neoplasm analyzed in a series of 29 cases. Am J Surg Pathol. 2007;31(12):1813-24.

54 Cosentino TB, Brazão-Silva MT, Souza KC, de Faria PR, de Moraes S, Loyola AM, et al. Myoepithelial carcinoma of the submandibular gland: report of a case with multiple cutaneous metastases. Oral Surg Oral Med Oral Pathol Oral Radiol Endod. 2008;106(2):e26-9.

55 Barnes L, Appel BN, Perez H, El-Attar AM. Myoepithelioma of the head and neck: case report and review. J Surg Oncol. 1985;28(1):21-8. 
56 Xiao CC, Baker AB, White-Gilbertson SJ, Day TA. Prognostic factors in myoepithelial carcinoma of the major salivary glands. Otolaryngol Head Neck Surg. 2016;154(6):1047-53.

57 Miccio JA, Oladeru OT, Xue Y, Yang J, Hoda ST, Ryu S, et al. Myoepithelial carcinoma and the role of radiation therapy: a case report and analysis of data from the Surveillance, Epidemiology, and End Results (SEER) registry. Int J Radiat Oncol Biol Phys. 2015;93(3):E630.

58 Bakst RL, Su W, Ozbek U, Knoll MA, Miles BA, Gupta V, et al. Adjuvant radiation for salivary gland malignancies is associated with improved survival: a National Cancer Database analysis. Adv Radiat Oncol. 2017;2(2):15966.

59 Nieder C, Schneller F, Grosu AL, Peschel C, Molls M. Radiotherapy and chemotherapy for myoepithelioma of the sellar region. Strahlenther Onkol. 2005;181(4):260-3.

60 Takayama O, Yokoyama J, Ito S. Therapeutic experience of recurrent myoepithelial carcinoma by superselective intra-arterial chemotherapy infused high-dose CDDP. Auris Nasus Larynx. 2006;33(2):235-8.

61 Noronha V, Cooper DL, Higgins SA, Murren JR, Kluger HM. Metastatic myoepithelial carcinoma of the vulva treated with carboplatin and paclitaxel. Lancet Oncol. 2006;7(3):270-1.

62 Freedman DM, Miller BA, Tucker MA. New malignancies following melanoma of skin, eye melanoma, and nonmelanoma eye cancer. In: Curtis RE, Freedman DM, Ron E, et al., editors. New malignancies among cancer survivors: SEER cancer registries, 1973-2000. Bethesda, MD: National Cancer Institute; 2006.

63 Bradford PT, Freedman DM, Goldstein AM, et al. Increased risk of second primary cancers after a diagnosis of melanoma. Arch Dermatol. 2010;146(3):265-72. 